Research Article

\title{
Characterizing Skeleton Structure and Stacking Properties of Continuous and Gap Graded Aggregate Mixtures
}

\author{
Dexiang Bao, ${ }^{1,2}$ Chen Jiaqi $\left(D^{D},{ }^{3}\right.$ Hao Wang, ${ }^{4}$ Huanjiao Liu, ${ }^{5}$ and Jiupeng Zhang ${ }^{5}$ \\ ${ }^{1}$ School of Civil Engineering, Lanzhou Jiaotong University, Lanzhou, Gansu 730070, China \\ ${ }^{2}$ Gansu Province Transportation Planning, Survey \& Design Institute Co., Ltd, Lanzhou, Gansu 730070, China \\ ${ }^{3}$ School of Civil Engineering, Central South University, Changsha, Hunan 410075, China \\ ${ }^{4}$ Department of Civil and Environmental Engineering, Rutgers, The State University of New Jersey, Piscataway, NJ 08854, USA \\ ${ }^{5}$ Key Laboratory for Special Area Highway Engineering of Ministry of Education, Chang'an University, Xi'an, \\ Shaanxi 710064, China
}

Correspondence should be addressed to Chen Jiaqi; chenjiaqi@csu.edu.cn

Received 20 March 2019; Revised 9 April 2019; Accepted 9 April 2019; Published 12 May 2019

Academic Editor: Ghassan Chehab

Copyright (C) 2019 Dexiang Bao et al. This is an open access article distributed under the Creative Commons Attribution License, which permits unrestricted use, distribution, and reproduction in any medium, provided the original work is properly cited.

In order to optimize the skeletal properties of granular pavement materials, a numerical discrete element model for continuous and gap graded aggregate mixtures was developed using a step-by-step filling method. The penetration tests were conducted, and indexes such as penetrating resistance, average coordination number, California bearing ratio, and void ratio of coarse aggregates obtained from the tests were used to evaluate the skeleton structure and the stacking properties of aggregate mixtures. The results show that the skeleton structure of aggregate mixtures is closely related to the combination of particle size. Smaller difference in particle size leads to stronger interference effect. The parameters of stacking properties of continuous and gap graded aggregate mixtures are not significantly different in the natural stacking condition. However, gap graded aggregate mixtures are affected by external loads significantly due to structural reconstruction.

\section{Introduction}

The continuous and gap graded aggregates mixtures are commonly used granular materials in the pavement structure. The mechanical properties of these granular materials should be properly evaluated due to their significant effect on the pavement performance. Although the mechanical properties of these pavement materials can be evaluated with traditional experiments from the macroperspective, extensive literatures show that the mesostructure of pavement materials should be further studied since it significantly affects the bulk material properties [1-3].

The discrete element method (DEM) has been widely used to study the mesoscopic properties of pavement materials, since it is an efficient method to simulate the interaction between granular particles [4-7]. Different algorithms have been developed to simulate the geometries of aggregates and ballasts [8-10], and various experiments such as the direct box shear tests, simple shear tests, triaxial tests, and others have been simulated with DEM. Song et al. simulated the mesostructure of the end soil in shield tunnels by using DEM [11]. The mesomechanism for the slipping damage of the end soil was discussed. In order to study the fracture behaviors of asphalt mixture, Chen and Huang conducted virtual center point beam tests with DEM and 2D microstructure of asphalt mixtures [12]. Besides of center point beam tests, virtual biaxial tests based on DEM were also reported in the literatures, to study the effect of particle size, confining pressures, and loading velocities on the elastic moduli, strength, and crack-initiation stress $[13,14]$. Lu and Mcdowell investigated the influence of the shape on the heterogeneous stresses within an aggregate and found that more angular shape led to a greater degree of homogeneity [15]. Uthus et al. simulated the resilient response of an unbound granular material subjected to sinusoidal loading in a triaxial sample [16]. Chen et al. conducted virtual process simulation test to investigate the lateral displacement of a granular assembly under cyclic loading [17]. 
In order to further investigate the skeleton structure and stacking properties of continuous and gap graded aggregate mixtures, virtual penetration tests based on DEM were conducted to study the CBR of different type of aggregate mixtures in this paper. The macro- and mesomechanical correlation of the mineral aggregate mixtures were developed. The optimal filling ratios for these aggregate mixtures were also recommended based on the analysis in this paper.

\section{Virtual Experiments and Parameters Calibration}

2.1. Development of Digital Specimens and Virtual Test. In this section, digital specimens of aggregate mixtures were developed and used for virtual penetration testing. The simulated aggregates were simplified as spheres with particle size between 4.75 and $16 \mathrm{~mm}$. Aggregate mixtures with different gradations were developed by using aggregates with different sizes. In general, the development process of the digital specimens and virtual testing was divided into three steps.

2.1.1. Generation of Digital Specimens. In this step, the digital specimens with the same dimensions as the specimens used in the CBR test were developed. Firstly, a virtual cuboid space with $150 \mathrm{~mm}$ in length, $150 \mathrm{~mm}$ in width, and $170 \mathrm{~mm}$ in height was set up for the placement of aggregates. Then, particles with different sizes were placed in the above virtual cuboid space randomly, considering the prescribed gradations. The placement of the particles was achieved by using specific flow code in PFC3D. In this process, due to the initial overlap between particles, unbalanced internal force would be caused between particles. In order to eliminate the overlap between particles, multiple cycles were applied to the specimen until the unbalanced internal force reached the minimum value. After this process, a cuboid specimen was developed as shown in Figure 1(a). In order to get the cylindrical specimen with the same dimensions as that used in the CBR test, an internal cylinder with $150 \mathrm{~mm}$ in diameter and $170 \mathrm{~mm}$ in height was cut from the above cuboid specimen. The particles inside the cylinder were kept, while the others were deleted, so that a cylindrical specimen of aggregate mixture was developed as shown in Figure 1(b).

2.1.2. Compaction of Digital Specimens. The CBR value of aggregate mixture was affected by the compaction state. Therefore, the loose digital specimens generated in Step (1) should be compacted before conducting virtual penetration test, in order to ensure adequate contact between particles. In this step, a vertical displacement with velocity of $1 \mathrm{~mm} / \mathrm{s}$ was applied to the top surface of the cylindrical specimen. During this process, the average contacts between particles within the blue sphere shown in Figure 1(c) were monitored and analyzed. When the change of the average contacts between particles became relative stable, the compaction of the digital specimen was completed.
2.1.3. Virtual Penetration Test. A penetration rod with $50 \mathrm{~mm}$ in diameter and $100 \mathrm{~mm}$ in height was generated, as shown in Figure 2. This rod was penetrated into the aggregate mixture with a constant velocity of $50 \mathrm{~mm} / \mathrm{min}$, until the penetration depth reached $20 \mathrm{~mm}$.

During this process, the displacement, stress, and pressure at the bottom of the rod were recorded and were used to calculate the CBR value according to equation (1), after the virtual testing was finished. The CBR value was calculated when the displacement was $2.5 \mathrm{~mm}$.

$$
\mathrm{CBR}=\frac{P \times 100}{7000} \text {. }
$$

2.2. Calibration of Mesoscopic Parameters. The mesoscopic parameters used in PFC3D should be calibrated before conducting numerical analysis, due to the lack of direct relationship between the macromechanical properties and the mesoscopic parameters [18]. In this paper, the singlevariable method was used to calibrate the mesoscopic parameters, including the friction coefficient, porosity, and contact stiffness ratio between particles, due to their important effect on the macroscopic properties of the bulk granular material reported in the literatures $[19,20]$.

The friction coefficient reflects the roughness of the contact surface between aggregates and usually ranges between 0 and 1 . In this section, the friction coefficient was taken as five different values, namely, 0.1,0.2, 0.3, 0.4, and 0.5. Virtual penetration test was conducted with these friction coefficient values, and the result was shown in Figure 3. Besides, seven different porosities $(0.2,0.25,0.3$, $0.35,0.4,0.45$, and 0.5$)$ and five different contact stiffness ratios $(1,2,3,4$, and 5) were selected to analyze the unit pressure with penetration of $5 \mathrm{~mm}$. The results are shown in Figures 4 and 5, respectively.

It can be seen from Figure 3, the simulation results with the friction coefficient of 0.4 matched with the measured values best. Therefore, the friction coefficient was taken as 0.4 in the following studies. Figures 3-5 also indicate that the penetration force was more sensitive to the friction coefficient and the porosity than the contact stiffness ratio. The porosity and the contact stiffness ratio were taken as 0.35 and 1, based on Figures 4 and 5, respectively.

2.3. Evaluation Indexes of Skeleton Structure and Stacking Properties. The CBR value is a commonly used index to evaluate the quality of the coarse aggregate skeleton structure $[21,22]$. The studies of stacking problem can be traced back to the famous Kepler conjecture and the 13-ball debate between Newton and Gregory. In 1968, Mason measured the position coordinates of randomly arranged smooth steel balls by the mosaic technique, and studied the geometrical indexes such as arrangement density, coordination number distribution frequency, and radial distribution function of this array [23]. Richard et al. [24] used X-ray Computed Tomography (CT) to study the variation of void ratios in the process of compacting of beads packing under vertical vibrations. In 2008, An et al. [25] analyzed the effect of 


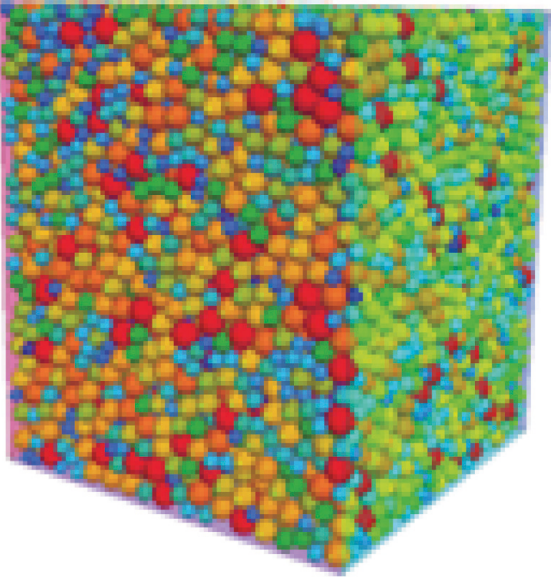

(a)

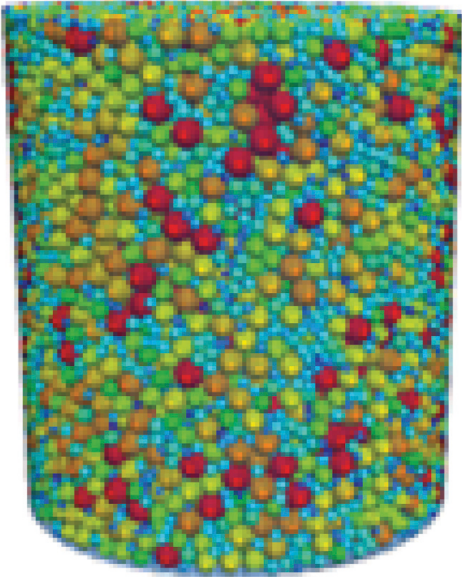

(b)

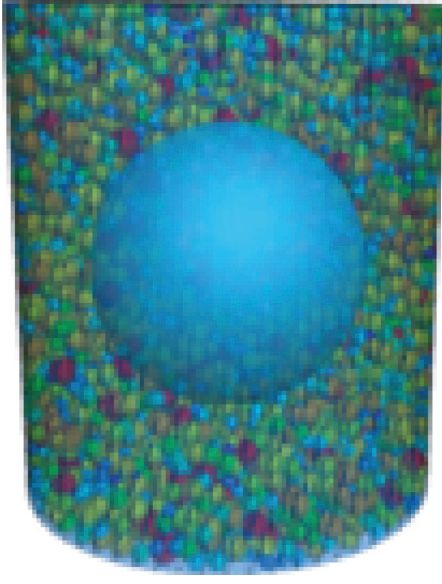

(c)

Figure 1: Digital simulation specimen.

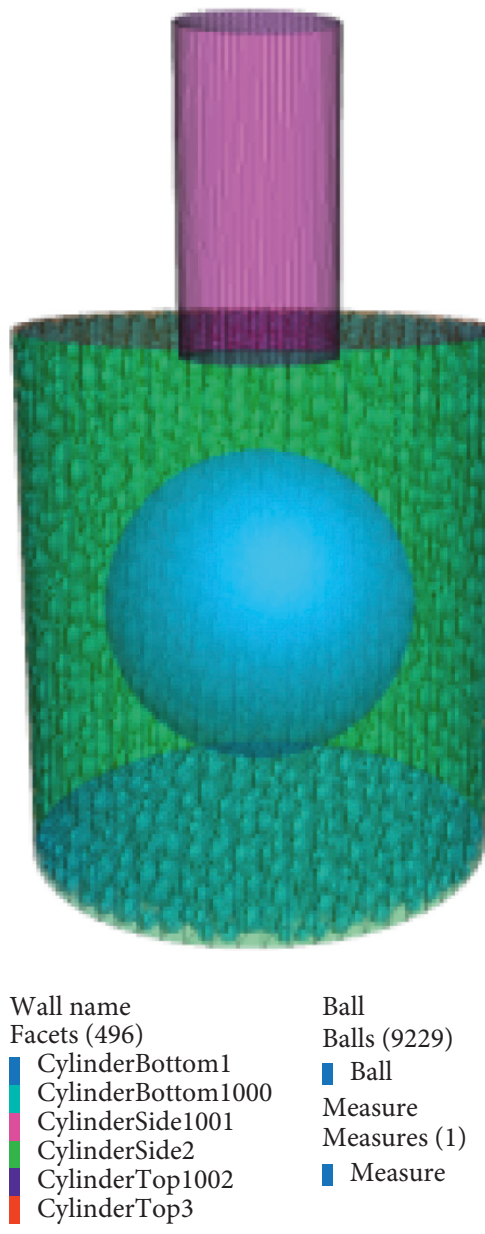

Figure 2: Penetration process.

amplitude, frequency, and friction coefficient on the coordination number, radial distribution equation, and void structure of the filling process using discrete element method. Mostofinejad and Reisi [26] simulated the filling of coarse aggregates, which were regarded as spheres with different sizes, and proposed a method for predicting the

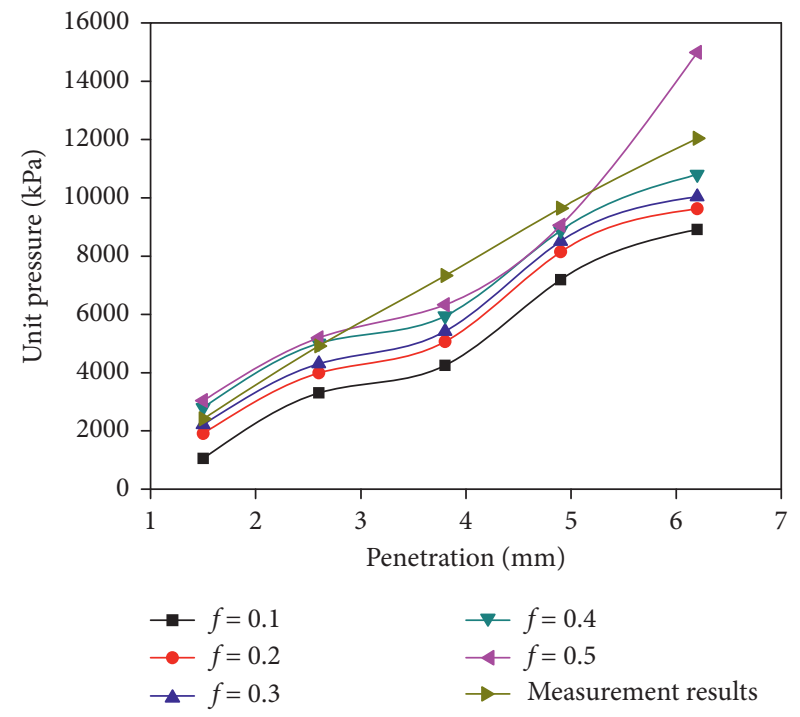

FIGURE 3: Unit pressure and penetration under different friction coefficients.

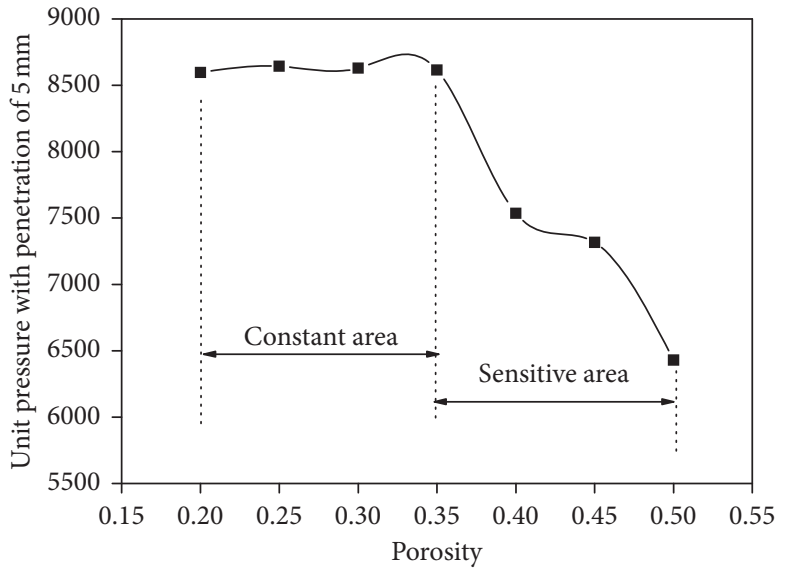

FIGURE 4: Variation in porosity. 


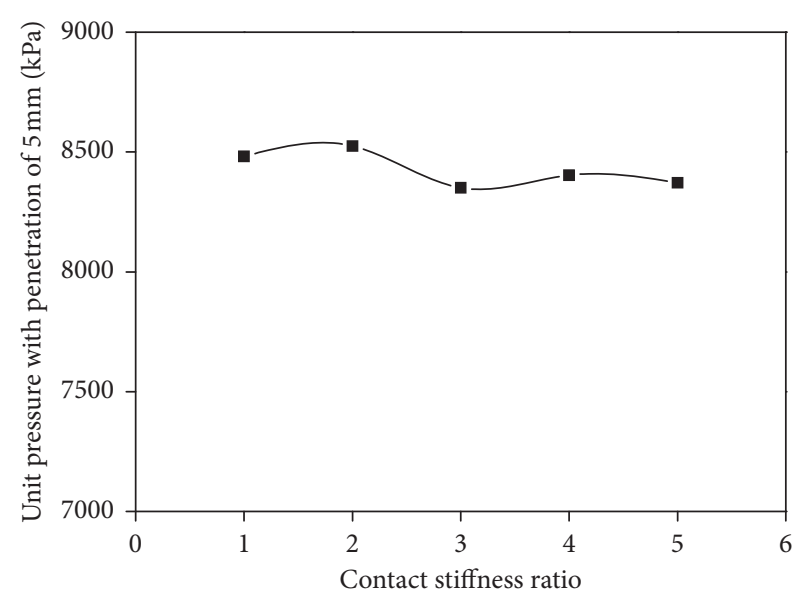

Figure 5: Variation in contact stiffness ratio.

internal void ratios of the aggregate mixtures. In this paper, indexes such as penetrating resistance, average coordination number, California bearing ratio, and void ratio of coarse aggregates were investigated.

\section{Characterizing Skeleton Structure of Mineral Aggregates Mixtures}

The effects of different aggregate combinations on the skeleton structure of mineral aggregate mixtures were studied based on the analysis of CBR, void ratio of coarse aggregates (VCA), and penetration resistance. A step-bystep filling method was used in the analysis. Studies show that aggregates with the particle size of $7.1 \mathrm{~mm}$ have significant influence on the void ratios of the mixture. Therefore, the progressive filling tests in this paper considered four different aggregate sizes and their combinations. The four different sizes of the aggregates were 13.2-16 mm (S1), 9.5-13.2 mm (S2), 7.1-9.5 mm (S3), and 4.75-7.1 mm (S4).

3.1. Skeleton Structure of Continuous Graded Aggregates. Based on the method of progressive filling and the principle of continuous gradation, the first-stage virtual filling tests were conducted. Three kinds of aggregate mixtures with two particle sizes and continuous gradation were prepared and were marked as S12, S23, and S34, respectively. S12 represented for the mixtures in which aggregates $\mathrm{S} 1$ were filled by the aggregates S2 with different proportions. Similarly, S23 represented for the mixtures in which aggregates S2 were filled by the aggregates S3 with different proportions. And S34 represented for the mixtures in which aggregates S3 were filled by the aggregates S4 with different proportions. The values of CBR and VCA of these three kinds of aggregate mixtures were obtained by PFC3D and are shown in Figure 6.

It can be seen that the variations of CBR and VCA for the three mixtures presented negatively correlated trends. The CBR value increased when the VCA value decreased and the CBR value decreased when the VCA value increased.
According to the filling interference principle, the pores in the skeleton structure of the coarse aggregates were filled with the secondary aggregates. However, the skeleton structure formed by the coarse aggregates would be interfered by the excessive secondary aggregates, resulting in the skeleton structure being broken and the CBR value decreasing. Therefore, the optimal filling ratio of each aggregate mixture was be obtained, namely, $\mathrm{S} 1: \mathrm{S} 2=57: 43$, $\mathrm{S} 2: \mathrm{S} 3=82: 18$, and $\mathrm{S} 3: \mathrm{S} 4=90: 10$, based on the principle that smaller VCA led to larger CBR of the skeleton capacity.

The secondary filling was performed based on the above three optimal combinations. Two kinds of aggregate mixtures with three particle sizes and continuous gradation were prepared and were marked as S123 and S234, respectively. S123 represented the mixtures in which S12 was filled by S3 with different proportions, and S234 represented the mixtures in which S23 was filled by S4 with different proportions. The values of CBR and VCA of the above two mixtures are shown in Figure 7.

It can be seen from Figure 7 (a) that the maximum CBR value was obtained when the mass content of S3 was $30 \%$. The skeleton compactness and skeleton strength of the combination were both good when the CBR value reached the maximum value and the VCA reached the minimum value. Therefore, the ratio of S12 to S3 was determined to be $70: 30$, which meant the optimal ratio between S1, S2, and S3 was $39.9: 30.1: 30$. It can be seen from Figure 7 (b) that the $\mathrm{CBR}$ value reached the maximum value when the mass content of S4 was $60 \%$. Therefore, the ratio of S23 to S4 was determined to be $40: 60$ and the optimal ratio between S2, S3, and S4 was 32.8:7.2:60.

The variation of the penetration pressure with the penetration displacement for different mixtures could be obtained during the penetration process. The penetration loads for different aggregate mixtures at the same penetration displacement of $6 \mathrm{~mm}$ were recorded. Different penetration loads for the three-aggregate mixtures with two particle sizes (S12, S23, and S34) and the two-aggregate mixtures with three particle sizes (S123 and S234) at the penetration displacement of $6 \mathrm{~mm}$ are shown in Figure 8 .

According to Figure 8, the variation trend of the penetration load for different mixtures was in accordance with the variation of the CBR value when the penetration displacement was $6 \mathrm{~mm}$, which increased at first and then decreased gradually. As for the penetration loads, the conclusion of S12>S23>S34 and S123>S234 could be obtained, which proved that the aggregates with larger particle sizes were the main part of skeleton structure. The compressive load was mainly transmitted through the stronger skeleton. Therefore, the mechanical characteristics for the skeleton structure of the aggregate mixtures could be expressed by both absolute differences between CBR and VCA curves and the variation curve of the penetration load at the same penetration depth.

3.2. Skeleton Structure of Gap Graded Aggregates Mixtures. Three kinds of aggregate mixtures with two particle sizes and gap gradation were prepared and were marked as S13, S14, 


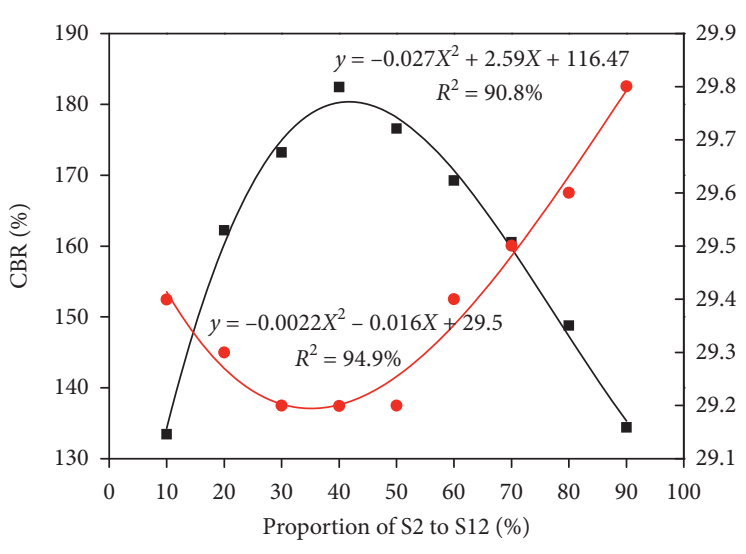

- CBR

- VCA

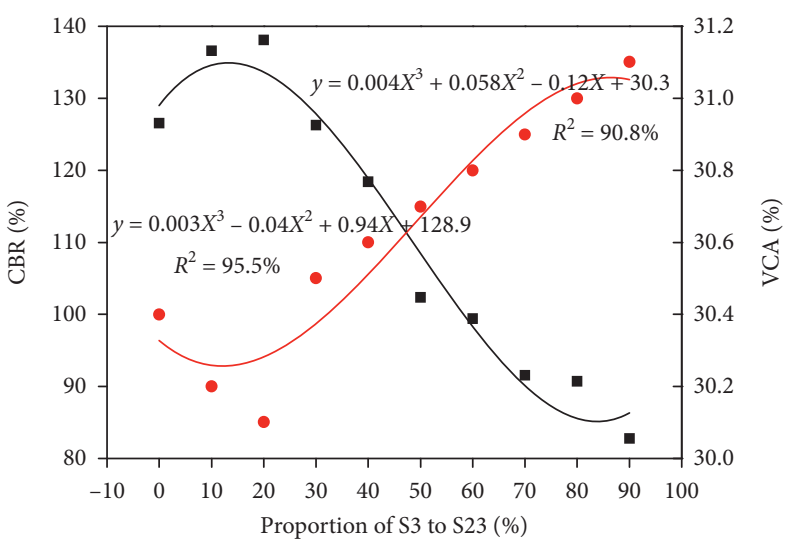

- CBR

- VCA

(a)

(b)

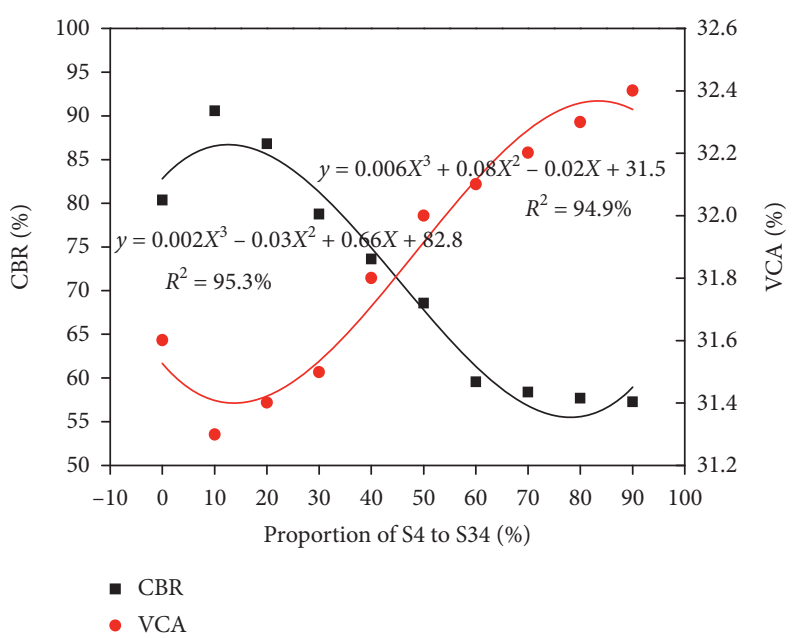

(c)

FIgURE 6: CBR and VCA of three kinds of two-aggregate mixtures with continuous gradation (a) S12, (b) S23, and (c) S34.

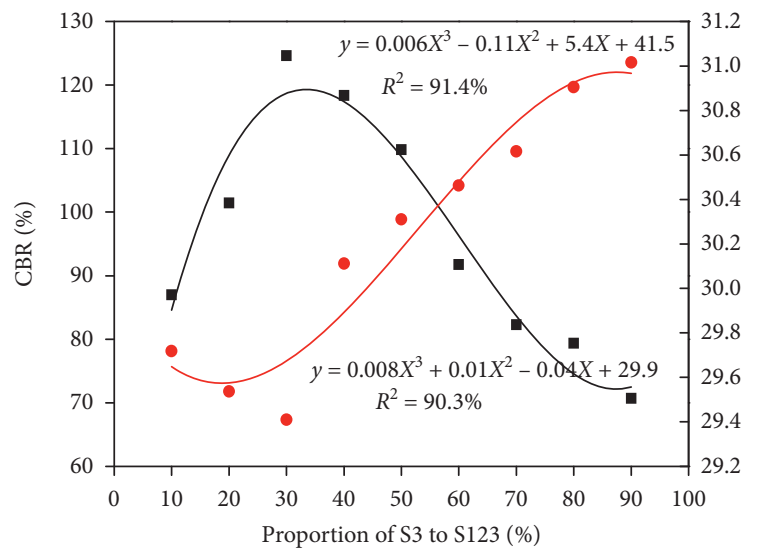

- CBR

- VCA

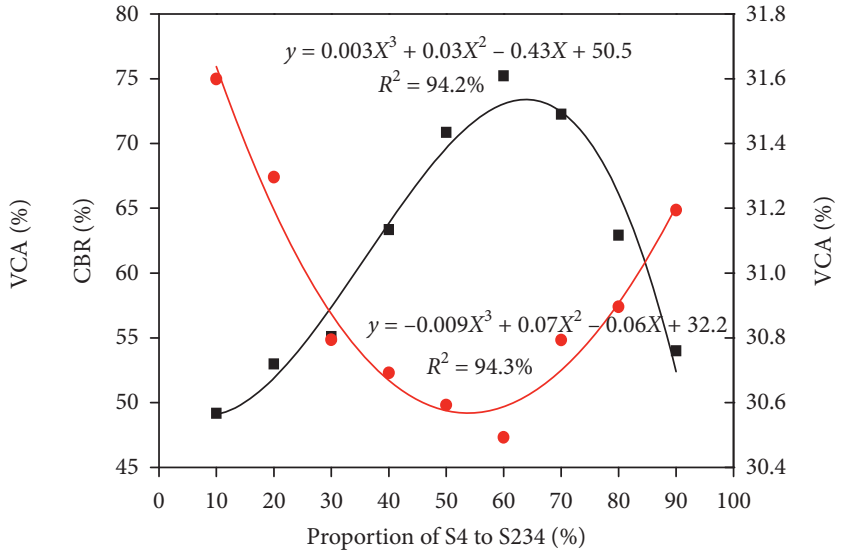

- CBR

- VCA

(a)

(b)

FigURE 7: CBR and VCA of two kinds of three-aggregate mixtures with continuous gradation (a) S123 and (b) S234. 


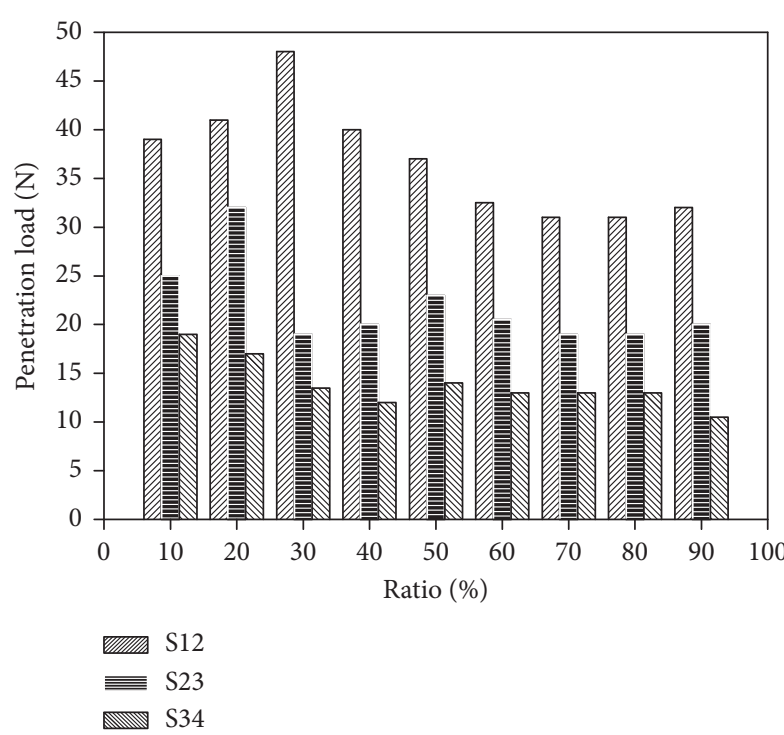

(a)

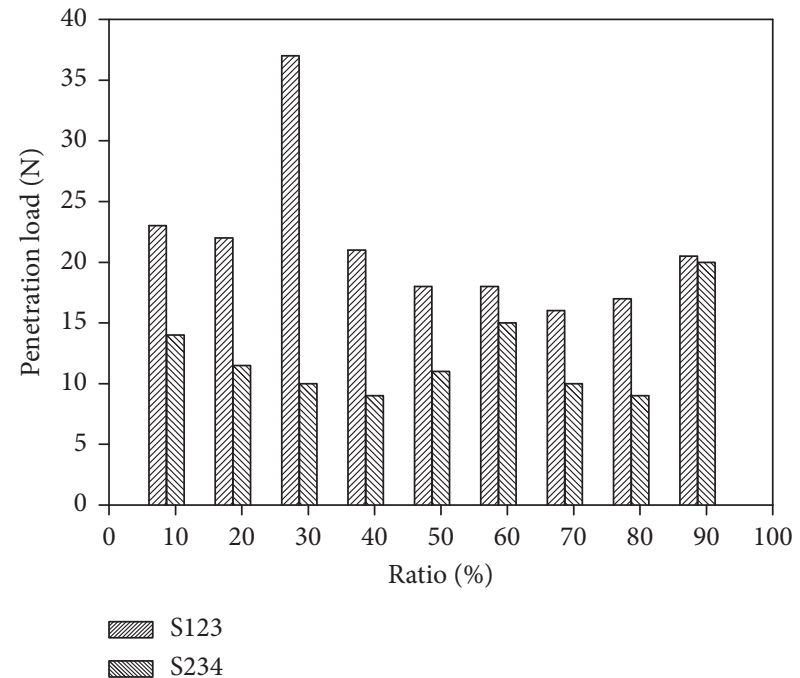

(b)

Figure 8: Penetration loads of five kinds of mixtures at the penetration displacement of $6 \mathrm{~mm}$ (a) two-aggregate mixtures and (b) threeaggregate mixtures.

and S24, respectively. S13 represents mixtures in which aggregates S1 were filled by the aggregates S3 with different proportions. Similarly, S14 represented the mixtures in which aggregates $S 1$ were filled by the aggregates $S 4$ with different proportions, and S24 represented the mixtures in which aggregates S2 were filled by the aggregates S4 with different proportions. The values of CBR and VCA of these three mixtures are shown in Figure 9.

It can be seen from Figure 9 that the optimal ratio could be determined as $\mathrm{S} 1: \mathrm{S} 3=75: 25, \mathrm{~S} 2: \mathrm{S} 4=90: 10$, and $\mathrm{S} 1$ : $S 4=40: 60$, based on the principle that smaller VCA led to greater skeleton load capacity characterized by CBR.

Two kinds of aggregate mixtures with three particle sizes and gap gradation were prepared and were marked as S124 and S134, respectively. S124 represented the mixtures in which $S 12$ was filled by $S 4$ with different proportions, and S134 represented the mixtures in which S13 was filled by S4 with different proportions. The values of CBR and VCA of these two mixtures are shown in Figure 10.

It can be seen from Figure 10 that the CBR values of these two mixtures increased firstly and then decreased later. The optimal ratio of S1 and S2 was $57: 43$, and the optimal ratio of S1 and S3 was $75: 25$. The optimal ratios of these gap graded aggregate mixtures with three particle sizes were determined as $\mathrm{S} 1: \mathrm{S} 2: \mathrm{S} 4=22.8: 17.2: 60$, and $\mathrm{S} 1: \mathrm{S} 3: \mathrm{S} 4=54: 8: 18$.

Different penetration loads for these gap graded aggregate mixtures with two or three particle sizes at the penetration displacement of $6 \mathrm{~mm}$ are shown in Figures 11 and 12.

It can be seen from Figures 11 and 12 that the mean penetration loads for the gap graded aggregate mixtures with three particle sizes were larger than that with two particle sizes, which proved that, for the load resistance, the gap graded aggregate mixtures with three particle sizes were better than that with two particle sizes. According to
Figure 11, the contribution rate on load resistance of S13 was greater than that of S14 and S24 for the gap graded aggregate mixtures with two particle sizes. It can be speculated that the contribution rate on load resistance of different aggregates rely on their particle size, and larger particle size leads to greater contribution rate.

3.3. Comparative Analysis for Continuous and Gap Graded Aggregates Mixtures. The CBR values of different secondary aggregate mixtures are shown in Figure 13. Figure 13 shows that the CBR values firstly increased and then decreased with the variation of the secondary aggregate contents for the continuous gradation. While for the gap gradation, this trend was not so obvious, especially for the mixture S134. The maximum value of CBR was about $125 \%$ for the continuous gradation aggregate mixtures and about $100 \%$ for the gap gradation aggregate mixtures. The CBR value for the gap gradation aggregate mixtures was smaller than that of the continuous gradation aggregate mixtures under different contents of the secondary aggregates.

\section{Characterizing Stacking Properties of Mineral Aggregates Mixtures}

4.1. Stacking Properties of Continuous Graded Aggregates Mixtures. The influence of the content of secondary aggregates on the VCA value is shown in Figure 14.

It can be seen from Figure 14 that with the increase of the content of the secondary aggregates, the void ratios of these mixtures firstly decreased and then increased. The VCA reached the minimum value when the content of the secondary aggregates was $30 \%$.

The variation of the initial average coordination number with the content of the secondary aggregates is shown in Figure 15. 


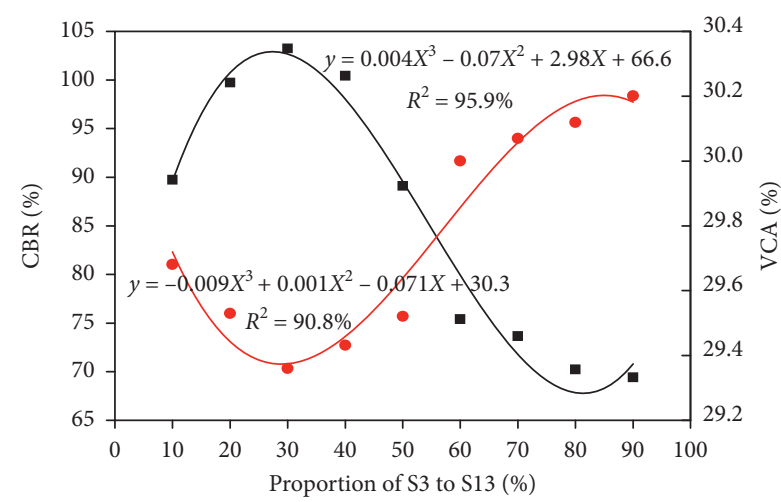

- CBR

- VCA

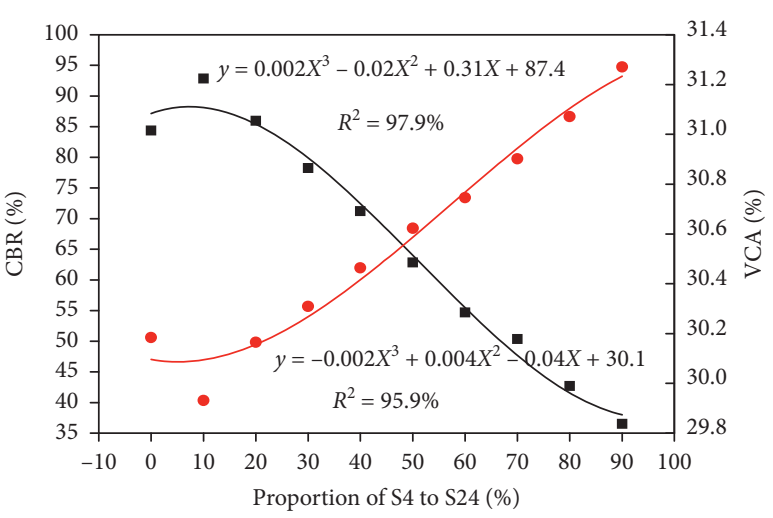

- CBR

- VCA

(a)

(b)

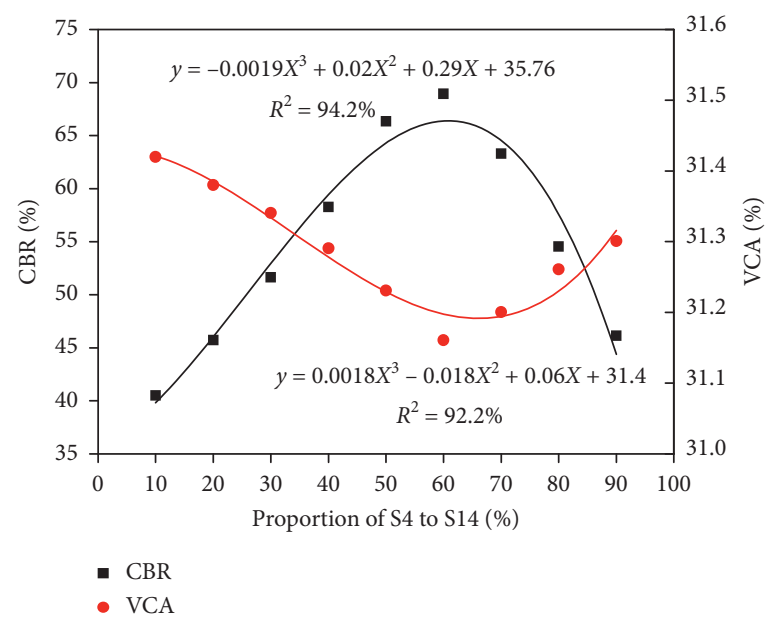

(c)

FIGURE 9: CBR and VCA of three kinds of two-aggregate mixtures with gap gradation (a) S13, (b) S24, and (c) S14.

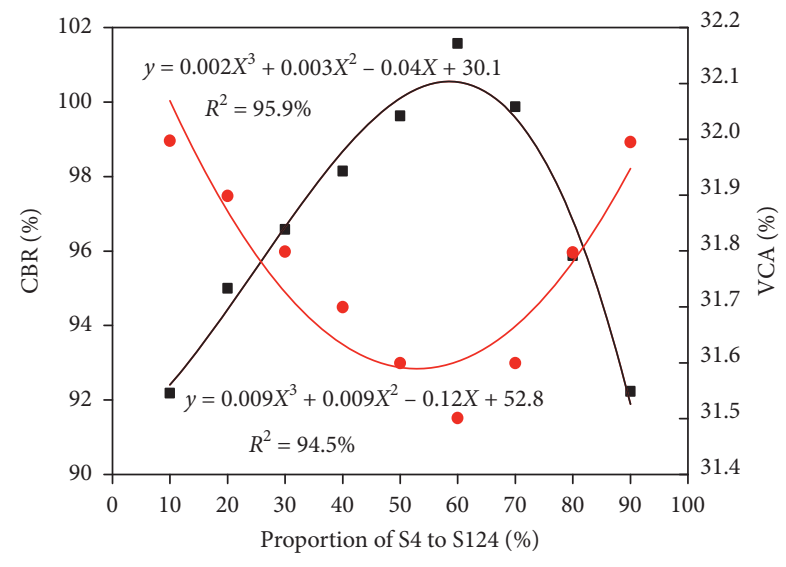

- CBR

- VCA

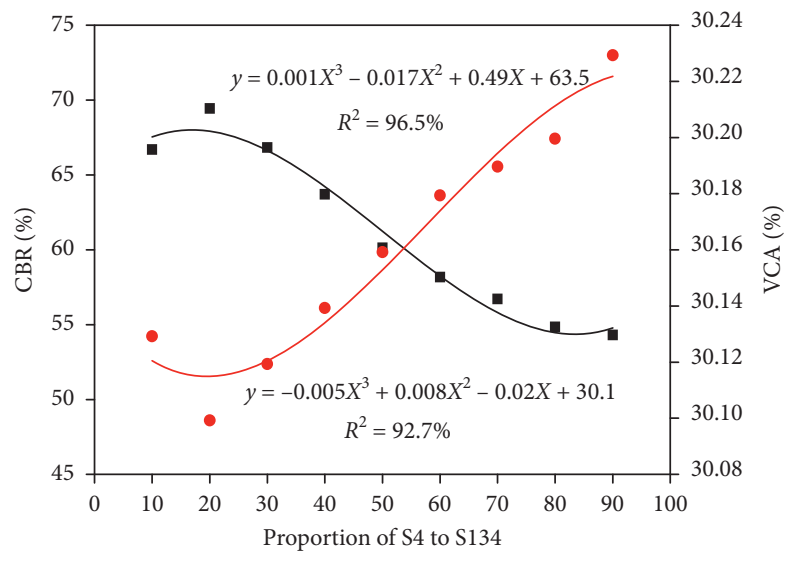

- CBR

- VCA

(a)

(b)

FIGURE 10: CBR and VCA of two kinds of three-aggregate mixtures with gap gradation (a) S124 and (b) S134. 


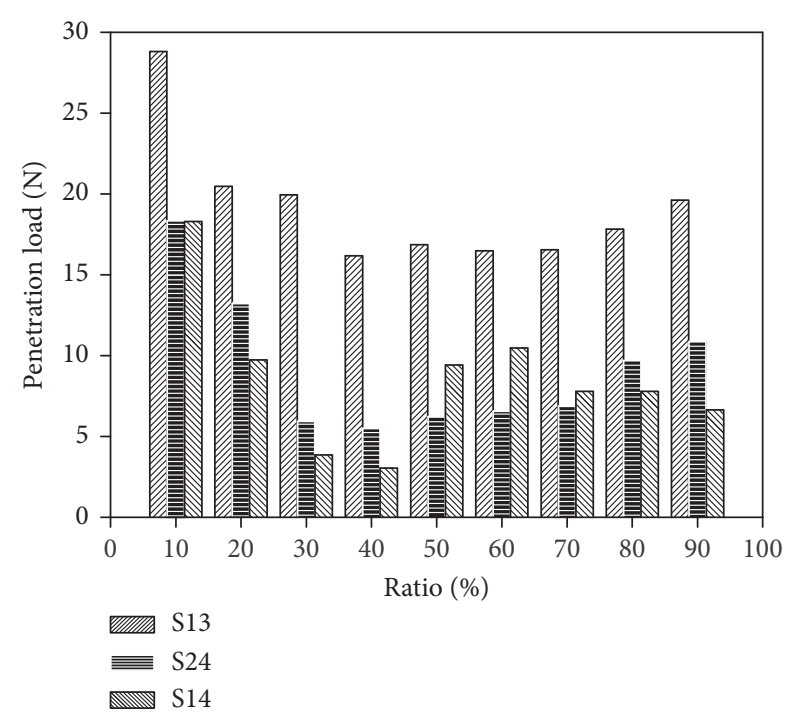

Figure 11: Penetration loads of three kinds of two-aggregate mixtures with gap gradation at the penetration displacement of $6 \mathrm{~mm}$.

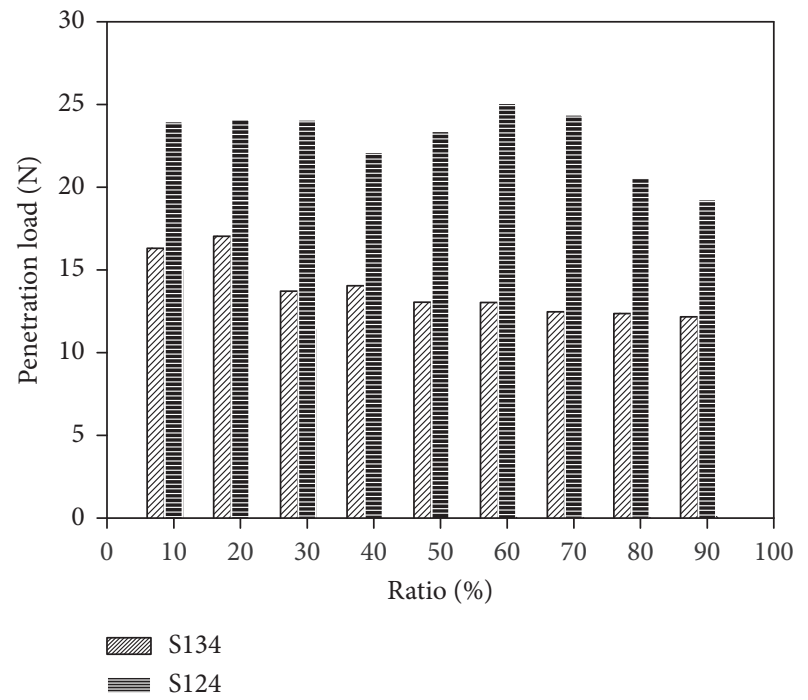

Figure 12: Penetration loads of two kinds of three-aggregate mixtures with gap gradation at the penetration displacement of $6 \mathrm{~mm}$.

It can be seen from Figure 15 that the variation of the initial average coordination number were less than $5 \%$, meaning that variation range of the initial average coordination number of the continuous graded mixtures was very small and could be treated as a constant.

According to the number of contact points and the number of particles collected during the penetration test, the average coordination numbers of the continuous graded mixtures were calculated by the weighted mean method and are shown in Figure 16, where $S$ represented the penetration displacement. It can be seen from Figure 16 that the average coordination numbers of the continuous graded mixtures increased with the increase of the displacement. Therefore, the conclusion is drawn that the good filling

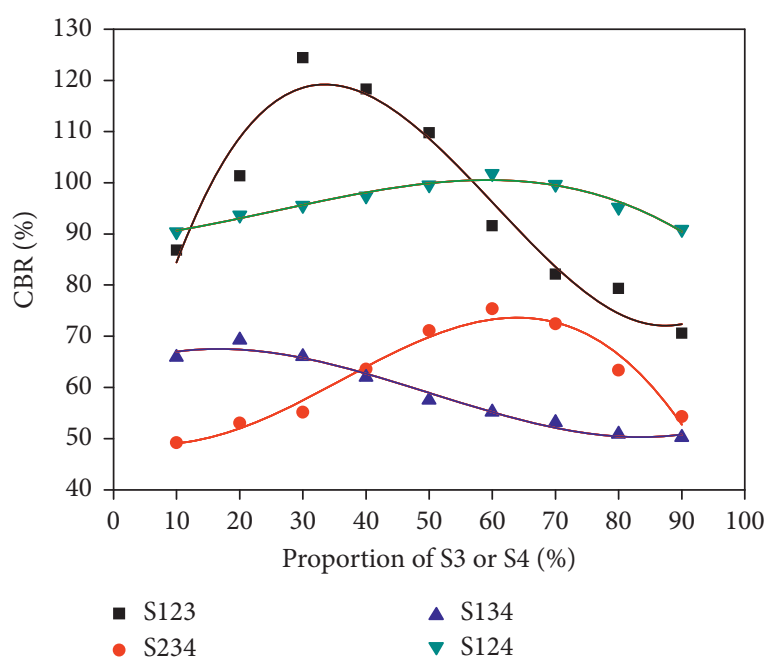

FIGURE 13: Influences on the CBR of different secondary aggregates mixtures.

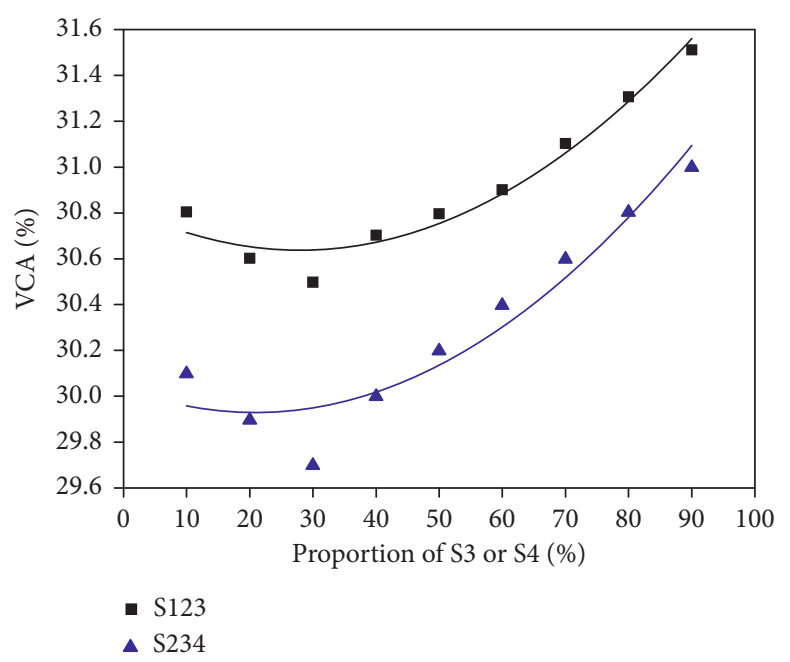

FIGURE 14: Influence of the content of secondary aggregate on the VCA.

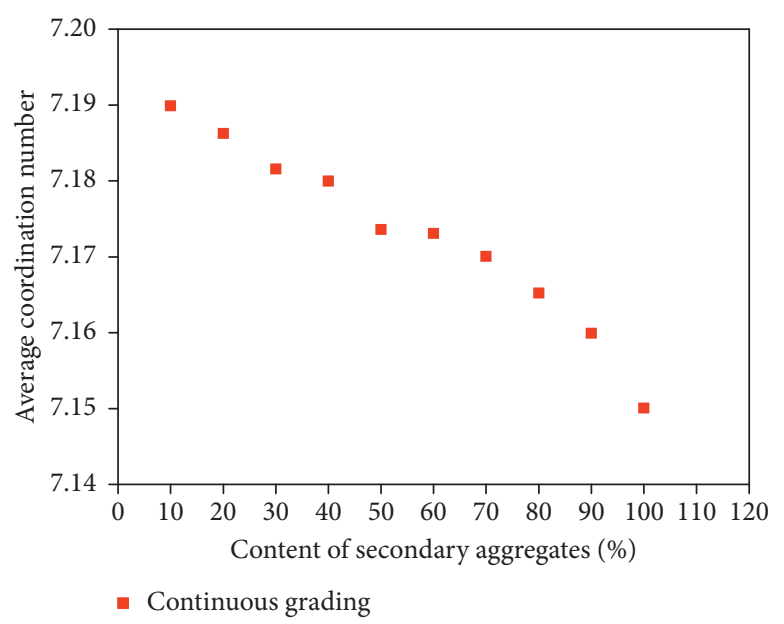

FIGURE 15: Variation of the initial average coordination number with the content of secondary aggregates. 


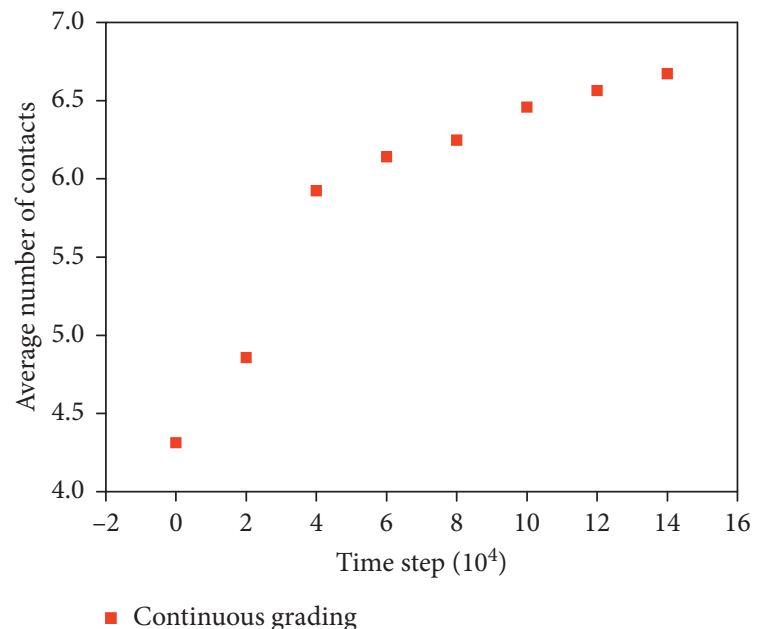

(a)

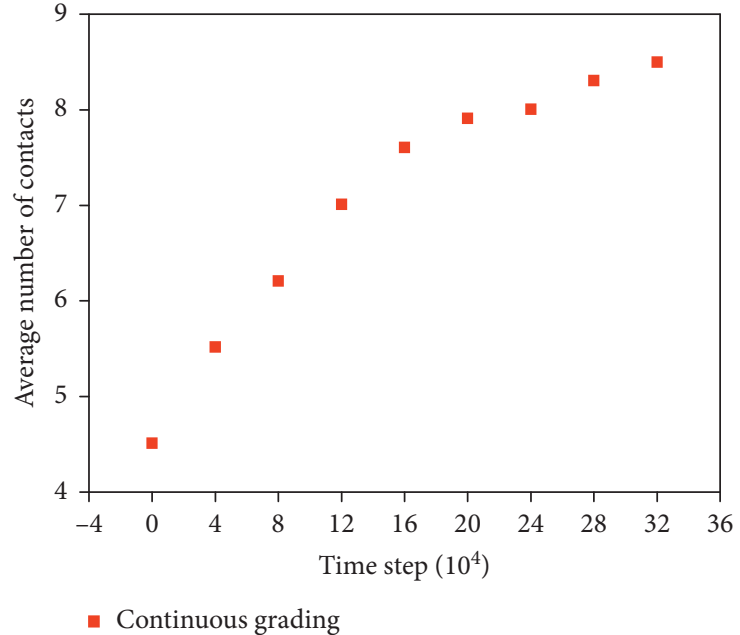

(b)

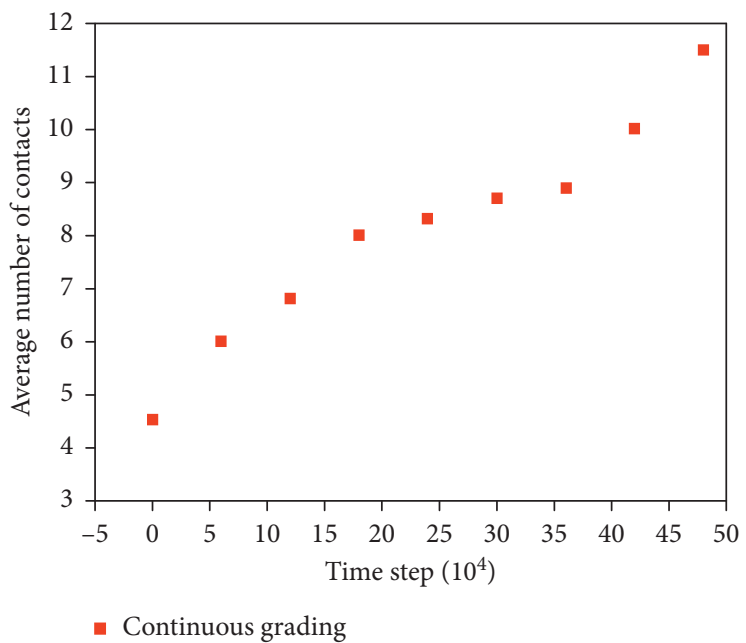

(c)

FIGURE 16: Variation of the average coordination numbers with different penetration displacements (a) $S=6 \mathrm{~mm}$, (b) $S=12 \mathrm{~mm}$, and (c) $S=20 \mathrm{~mm}$.

skeleton structure is formed for the continuous gradation mixtures, and the structure properties can ensure a good condition under the load.

4.2. Stacking Properties of Gap Graded Aggregates Mixtures. The VCA of the gap graded aggregate mixtures with three particle sizes is shown in Figure 17.

It can be seen from Figure 17 that with the increasing content of the secondary aggregates, the void ratios of these mixtures firstly increased and then decreased. The minimum value of the VCA was obtained when the content of the secondary aggregates was $62 \%$. There are many studies on the distribution of the coordination numbers for single sized aggregates, but little study has been conducted on the distribution of the coordination numbers for the multisized aggregates. The paper reveals that the correlation between the average coordination number and the VCA of mixtures with multisized particles is similar with the mixtures consisting of single-sized aggregates, namely, the average coordination number increases with the decrease of the VCA [27].

The variation of the initial average coordination number of the gap graded mixtures with the content of the secondary aggregates is shown in Figure 18. It can be seen from Figure 18 that the variation of the initial average coordination number of the gap graded mixtures is not significant (less than $5 \%$ ).

The average contact numbers of the continuous graded mixtures under different penetration displacements were calculated. The results are shown in Figure 19.

As for the mixtures with gap gradation, it can be seen from Figure 19 that the average coordination number increased all the time when $S=6 \mathrm{~mm}$. While when $S=12 \mathrm{~mm}$, the average coordination number firstly increased and then decreased. When $S=20 \mathrm{~mm}$, the average coordination number firstly increased and then decreased, but finally increased again. 


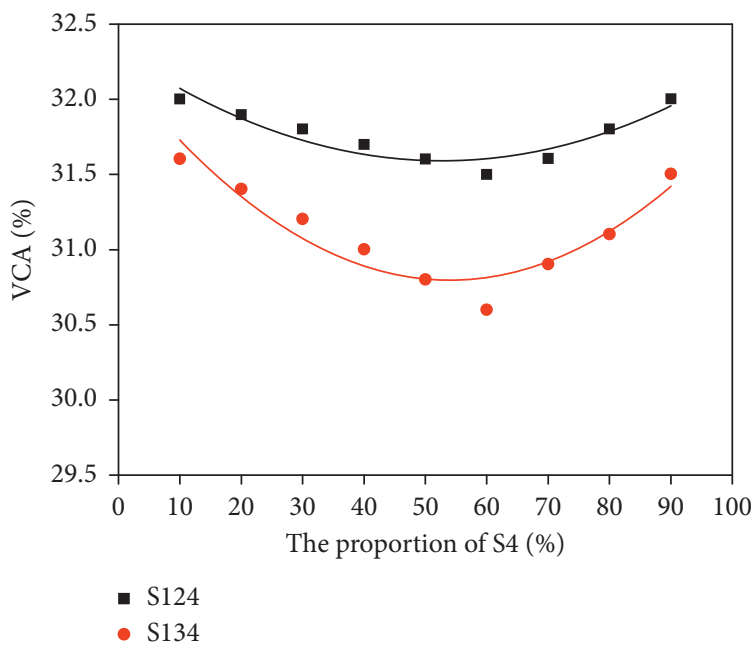

FIGURE 17: Influence of the content of secondary aggregates on the VCA.

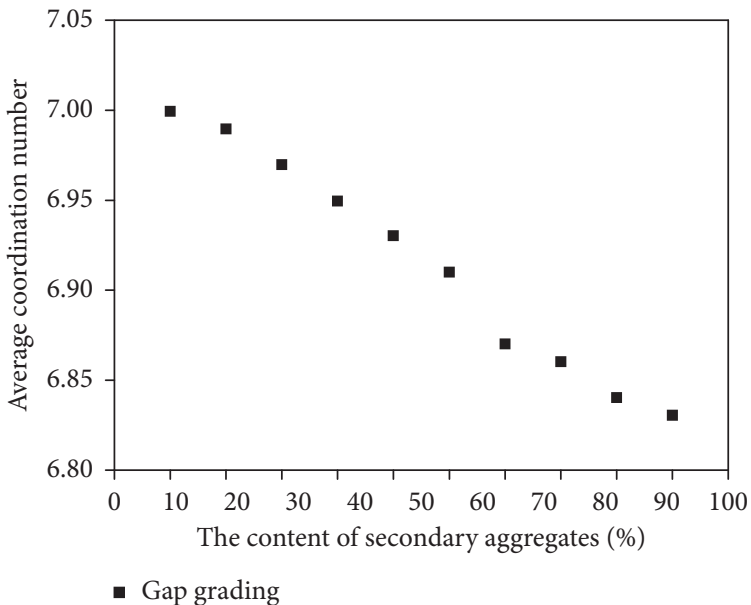

FIGURE 18: Variation of the average coordination number with the content of secondary aggregates.

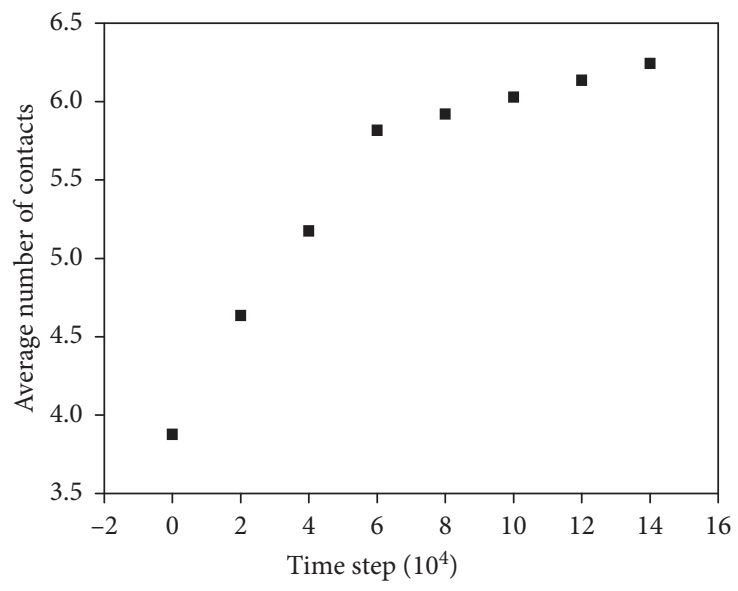

- Gap grading

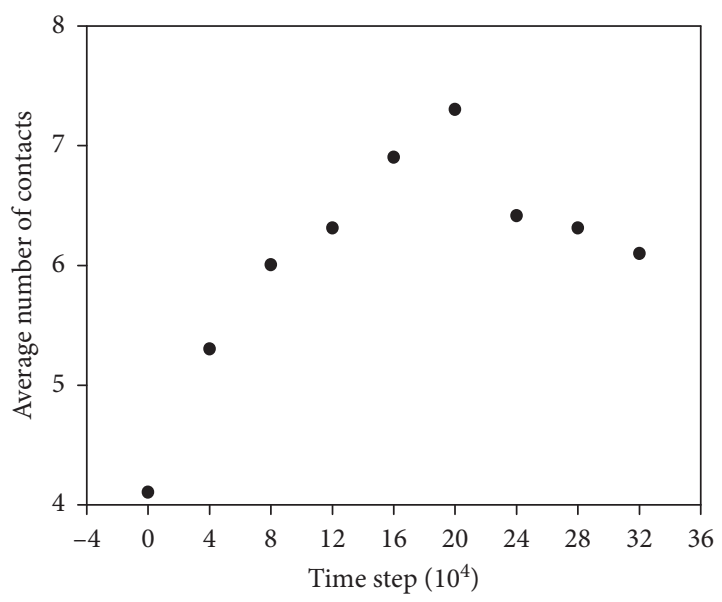

- Gap grading

(a)

(b)

Figure 19: Continued. 


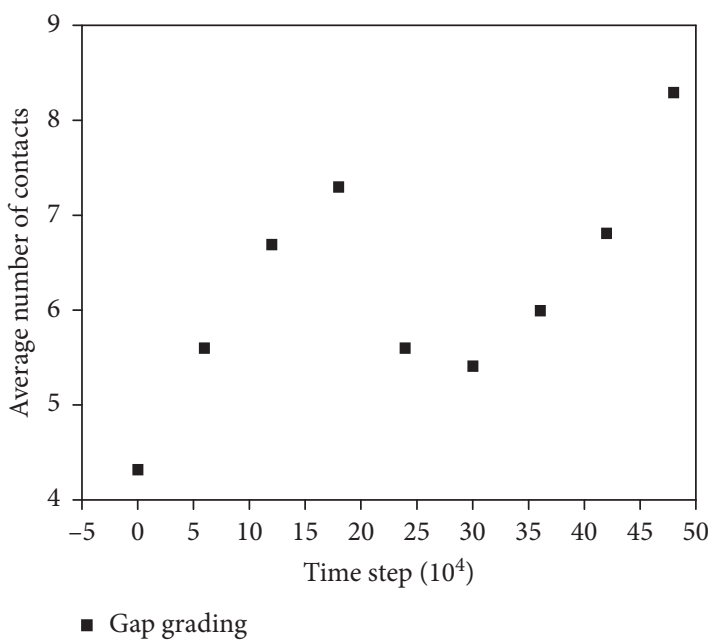

(c)

Figure 19: Variation of the average coordination numbers with different penetration displacements (a) $S=6 \mathrm{~mm}$, (b) $S=12 \mathrm{~mm}$, and (c) $S=20 \mathrm{~mm}$.

\subsection{Comparative Analysis for Continuous and Gap Graded} Aggregates Mixtures. The influence of the content of the secondary aggregates on the VCA is shown in Figure 20.

It can be seen from Figure 20 that the VCA values firstly decreased and then increased with the variation of the secondary aggregate contents both for the continuous and gap gradation aggregate mixtures. The minimum value of VCA was about $30 \%$ for the continuous gradation aggregate mixtures and $60 \%$ for the gap gradation aggregate mixtures. The VCA value for the gap gradation aggregate mixtures was larger than that of the continuous gradation aggregate mixtures under different contents of the secondary aggregates.

The variation of the average coordination number with volume fractions of smaller sized aggregates for the continuous and gap gradation mixtures is shown in Figure 21.

It can be seen from Figure 21 that the variation of the average coordination number for the gap gradation mixtures was larger than that of the continuous gradation mixtures, meaning that the staking characteristics of gap graded mixtures was easy to be influenced by the content of the secondary aggregates.

The average contact numbers of the mixtures with continuous and gap gradation in the case of different penetration displacements were calculated. The results are shown in Figure 22.

It can be seen from Figure 22 that the average coordination numbers of the mixtures depended on the penetration displacement. For the continuous gradation mixtures, the average coordination number would increase evenly with the increase of the penetration displacement. As for the gap gradation mixtures, the average coordination number increased all the time when $S=6 \mathrm{~mm}$, while increased firstly and then decreased when $S=12 \mathrm{~mm}$. When $S=20 \mathrm{~mm}$, the average coordination number firstly increased and then decreased, but finally increased again. It shows that the external load disturbed the gap gradation mixtures significantly, and the reorganization occurred in the particle mixture structure during the penetration process.

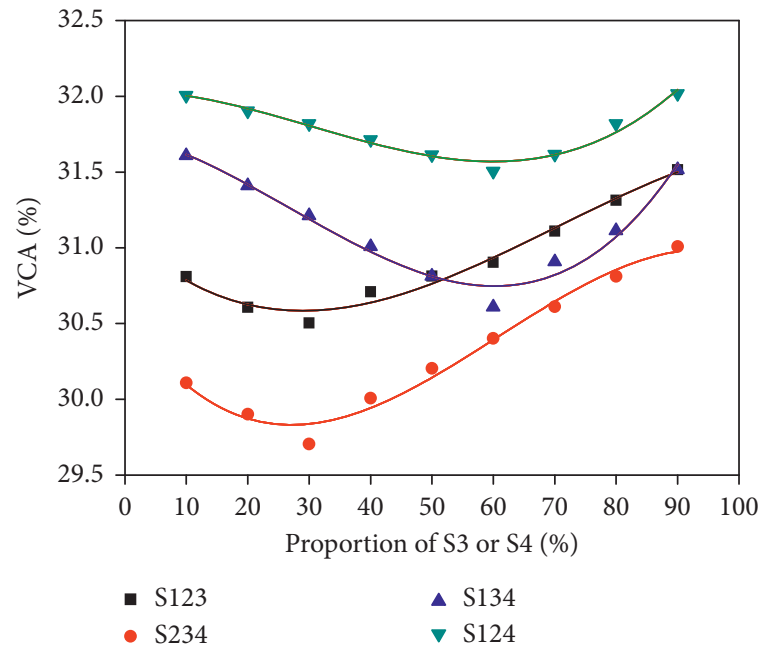

FIGURE 20: Influence of the content of secondary aggregates on the VCA.

\section{Conclusions}

In this paper, DEM was adopted to simulate the stacking behavior and the bearing capacity of continuous and gap graded aggregate mixtures. The evolution rule of aggregate particles under different penetration displacements was quantitatively analyzed. The main conclusions are shown as follows:

(1) The values of CBR and VCA for the continuous and gap graded aggregate mixtures were obtained under different contents of the secondary aggregates based on virtual penetration tests. The simulation results indicated that the relationship between CBR and VCA was negatively correlated. The optimal filling ratio of these aggregates mixtures was proposed.

(2) The skeleton structure of mineral aggregates mixtures was analyzed. The CBR value increased firstly 


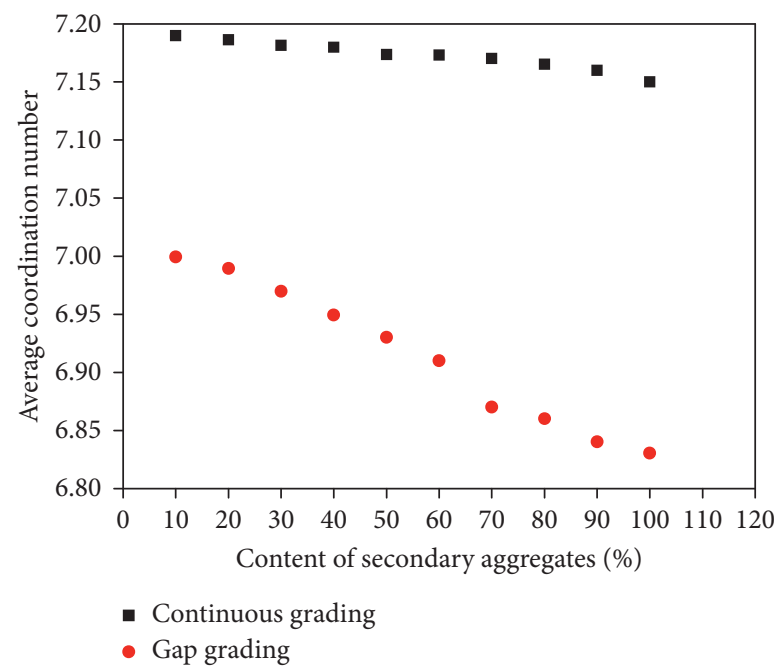

FigURE 21: Variation of the average coordination number with the content of the secondary aggregates.
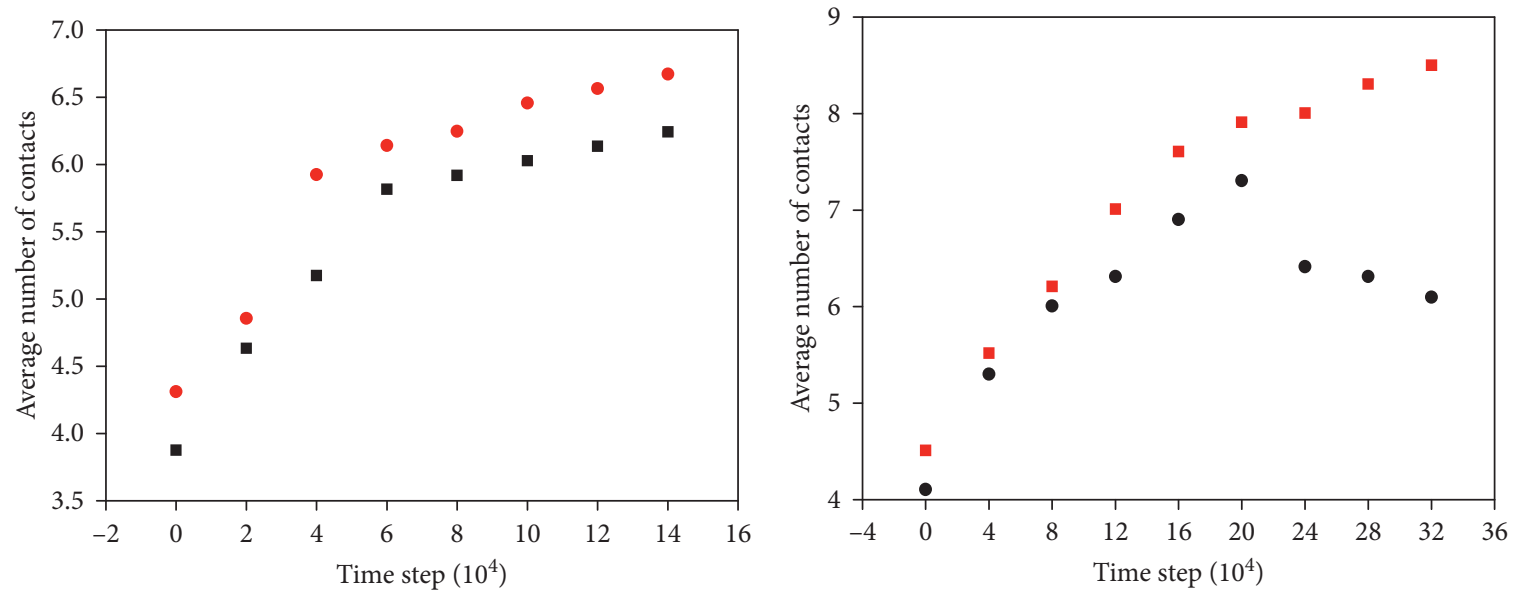

- Continuous grading

- Continuous grading

- Gap grading

- Gap grading

(a)

(b)

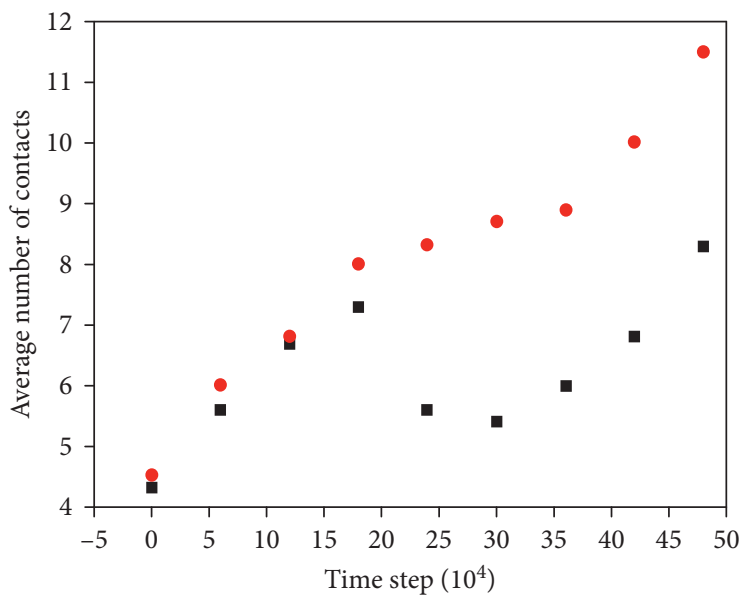

- Continuous grading

- Gap grading

(c)

Figure 22: Variation of the average coordination numbers with different penetration displacements: (a) $S=6 \mathrm{~mm}$, (b) $S=12 \mathrm{~mm}$, and (c) $S=20 \mathrm{~mm}$. 
and then decreased with the increasing content of the secondary aggregates for the continuous and gap graded aggregates mixtures. However, the variation of CBR values for the continuous graded aggregates mixtures was larger than that for the gap gradation aggregates mixtures, meaning that the smaller the difference of particle size is, the stronger the interference effect is.

(3) Comparative analysis of stacking properties of mineral aggregate mixtures was conducted to conclude that the parameters of stacking properties of mineral aggregate mixtures with the continuous and gap gradation are not significantly different under natural stacking. But the gap graded aggregates mixtures are affected by external loads obviously resulting in structure reorganization.

\section{Appendix}

\section{An Example of Code Used in This Paper}

new

title "CBR"

domain extent $-0.20 .2-0.20 .200 .4$ condition destroy cmat default model linear method deformability emod 1e9 kratio 1.0

contact property fric 0.4 range contact type ball-ball

cmat default property dp_nratio 0.2

set random 10002

ball distribute porosity 0.36 numbin $2 \ldots$

bin 1 radius 0.001180 .002375 volumefraction $0.15 \ldots$

bin 2 radius 0.0023750 .00475 volumefraction $0.85 \ldots$

box $-0.0750 .075-0.0750 .07500 .17$

wall gen box $-0.0750 .075-0.0750 .07500 .17$

ball attribute density 3000 damp 0.7

cycle 50000 calm 10

save S1_1.p3sav

wall delete

ball delete range cylinder end 10000 end 2000.17 rad 0.075 not

wall generate cylinder base 000 height 0.17 radius 0.075

wall del facets range id 436496

wall gen id 1000 cylinder base 000.17 height 0.1 radius 0.025

save S1_2.p3sav

cyc 2000

ball attribute displacement multiply 0.0

contact property lin_force 0.00 .00 lin_mode 1

ball attribute contactforce multiply 0.0 contactmoment multiply 0.0

save S1_3.p3sav cyc 2000

ball attribute displacement multiply 0.0

contact property lin_force 0.00 .00 lin_mode 1

ball attribute contactforce multiply 0.0 contactmoment multiply 0.0

wall attribute zvel -0.1 rang id 10001002

wall hist id 30 contactforce id 1000

wall hist id 40 zdisp id 1000

measure creat id 20 x 0 y $0 \mathrm{z} 0.08 \mathrm{rad} 0.05$

measure hist id 200 coord id 20

measure hist id 210 poro id 20

measure hist id 220 stressxx id 20

measure hist id 230 stresszz id 20

cyc 90000

save S1_4.p3sav

\section{Data Availability}

The data used to support the findings of this study are available from the corresponding author upon request.

\section{Conflicts of Interest}

The authors declare that they have no conflicts of interest.

\section{Acknowledgments}

This work was supported by the Department of Science and Technology of Shaanxi Province (nos. 2016ZDJC-24 and 2017KCT-13), China Postdoctoral Science Foundation (nos. 2017M620434), the Special Fund for Basic Scientific Research of Central College of Chang'an University (nos. 310821153502 and 310821173501), and International Cooperation Project of Jiangsu Province (no. BZ 2017011). The authors gratefully acknowledge their financial support.

\section{References}

[1] J. Li, J. Zhang, G. Qian, J. Zheng, and Y. Zhang, "Threedimensional simulation of aggregate and asphalt mixture using parameterized shape and size gradation," Journal of Materials in Civil Engineering, vol. 31, no. 3, article 04019004, 2019.

[2] J. Chen, R. Chu, H. Wang, and P. Xie, "Experimental measurement and microstructure-based simulation of thermal conductivity of unbound aggregates," Construction and Building Materials, vol. 189, pp. 8-18, 2018.

[3] J. Zhang, X. Li, W. Ma, and J. Pei, "Characterizing heterogeneity of asphalt mixture based on aggregate particles movements," Iranian Journal of Science and Technology, Transactions of Civil Engineering, vol. 43, no. 1, pp. 81-91, 2019.

[4] H. Dan, Z. Zhang, J. Chen, and H. Wang, "Numerical simulation of indirect tensile test for asphalt mixture with discrete element method software," Journal of Materials in Civil Engineering, vol. 30, no. 5, article 04018067, 2018.

[5] T. Ma, H. Wang, D. Zhang, and Y. Zhang, "Heterogeneity effect of mechanical property on creep behavior of asphalt 
mixture based on micromechanical modeling and virtual creep test," Mechanics of Materials, vol. 104, pp. 49-59, 2017.

[6] N. Li, B. Ma, H. Wang, J. Zhao, H. Wang, and X. Wang, "Numerical simulation of dynamic repetitive load test of unbound aggregate using precision unbound material analyzer," Road Materials and Pavement Design, pp. 1-19, 2019.

[7] H. Huang, Discrete element modeling of railroad ballast using imaging based aggregate morphology characterization, Ph.D. thesis, University of Illinois at Urbana, Champaign, IL USA, 2009.

[8] D. Zhang, X. Huang, and Y. Zhao, "Algorithms for generating three-dimensional aggregates and asphalt mixture samples by the discrete-element method," Journal of Computing in Civil Engineering, vol. 27, no. 2, pp. 111-117, 2013.

[9] N. Ouhbi, C. Voivret, G. Perrin, and J. N. Roux, “3D particle shape modelling and optimization through proper orthogonal decomposition," Granular Matter, vol. 19, no. 4, p. 86, 2017.

[10] X. Garcia, J.-P. Latham, J. Xiang, and J. P. Harrison, "A clustered overlapping sphere algorithm to represent real particles in discrete element modelling," Géotechnique, vol. 59, no. 9, pp. 779-784, 2009.

[11] K. Song, H. Hou, G. Liu, and J. Li, "Meso-mechanic behavior of soil damage of geotechnical engineering using DEM," Journal of Basic Science and Engineering, vol. 24, no. 3, pp. 618-631, 2016.

[12] J. Chen and X. Huang, "Virtual fracture test of asphalt mixture based on discrete element method," Journal of Southeast University (English Edition), vol. 25, no. 4, pp. 518-522, 2009.

[13] M. Chang, J. Pei, and S. Chen, "Numerical simulation of biaxial test for granular materials based on discrete element method," Journal of Traffic and Transportation Engineering, vol. 10, no. 5, pp. 1-7, 2010.

[14] M. Chang, J. Pei, and S. Chen, "Numerical simulation study of biaxial test for bonded granular material," Materials Review, vol. 25, no. 8, pp. 127-130, 2011.

[15] M. Lu and G. R. Mcdowell, "The importance of modelling ballast particle shape in the discrete element method," Granular Matter, vol. 9, no. 1-2, pp. 69-80, 2007.

[16] L. Uthus, M. A. Hopkins, and I. Horvli, "Discrete element modelling of the resilient behaviour of unbound granular aggregates," International Journal of Pavement Engineering, vol. 9, no. 6, pp. 387-395, 2008.

[17] C. Chen, B. Indraratna, G. McDowell, and C. Rujikiatkamjorn, "Discrete element modelling of lateral displacement of a granular assembly under cyclic loading," Computers and Geotechnics, vol. 69, pp. 474-484, 2015.

[18] J. Zhou, L. Zhang, F. Dai, and H. Min, "Numerical simulation of direct shear tests for rock and soil mixture in a landslide based on bonded-particle model," Chinese Journal of Rock Mechanics and Engineering, vol. 31, no. s2, pp. 4058-4067, 2012.

[19] B. Zhou, H. Wang, W. Zhao, J. Li, and B. Zheng, "Analysis of relationship between particle mesoscopic and macroscopic mechanical parameters of cohesive materials," Rock and Soil Mechanics, vol. 33, no. 10, pp. 3171-3178, 2012.

[20] G. Xu, Y. Shen, and H. L. Liu, "Analysis of particle flow for impacts of granular parameters and porosity on silt's properties under biaxial compression," Rock and Soil Mechanics, vol. 34, no. 11, pp. 3321-3328, 2013.

[21] X. Dai, Y. Jiang, J. Ren, G. Dong, T. Sun, and G. Liu, "CBR particle flow simulation of aggregate and design of coarse aggregate skeleton gradation with strong interlocked force,"
Journal of Traffic and Transportation Engineering, vol. 11, no. 3, pp. 10-15, 2011.

[22] Y. J. Jiang, J. L. Ren, D. Li, and Y. S. Xu, "Investigation into close-grained gradation of aggregates skeleton under strong interlocked force via PFC2D numerical test," Journal of South China University of Technology (Nature Science Edition), vol. 40, no. 2, pp. 92-98, 2012.

[23] G. Mason, "Radial distribution functions from small packings of spheres," Nature, vol. 217, no. 5130, pp. 733-735, 1968.

[24] P. Richard, P. Philippe, F. Barbe, S. Bourlès, X. Thibault, and D. Bideau, "Analysis by X-ray microtomography of a granular packing undergoing compaction," Physical Review E, vol. 68, no. 2, article 020301, 2003.

[25] X. Z. An, R. Y. Yang, R. P. Zou, and A. B. Yu, "Effect of vibration condition and inter-particle frictions on the packing of uniform spheres," Powder Technology, vol. 188, no. 2, pp. 102-109, 2008.

[26] D. Mostofinejad and M. Reisi, "A new DEM-based method to predict packing density of coarse aggregates considering their grading and shapes," Construction and Building Materials, vol. 35, pp. 414-420, 2012.

[27] L. J. H. Alberts, Initial porosity of random packing: computer simulation of grain rearrangement, Ph.D. thesis, Delft University of Technology, Delft, Netherlands, 2005. 


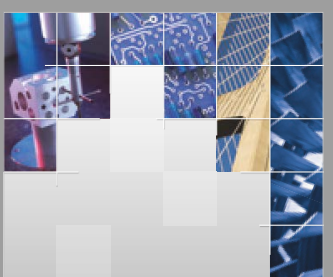

\section{Enfincering}
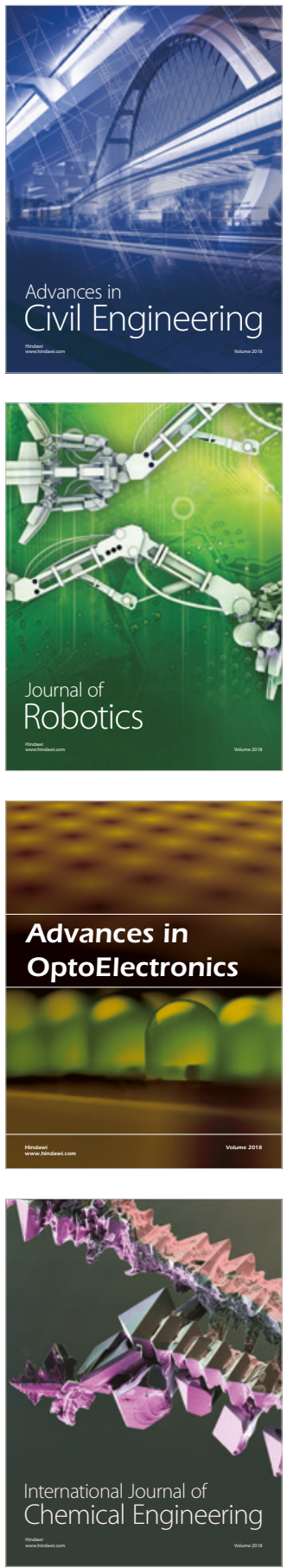

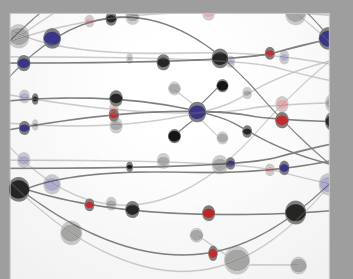

\section{Rotating \\ Machinery}

The Scientific World Journal

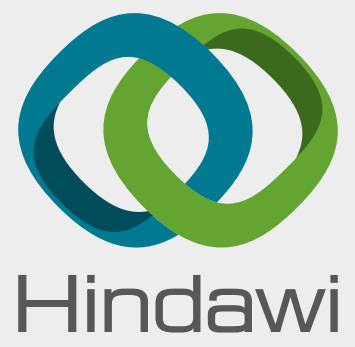

Submit your manuscripts at

www.hindawi.com
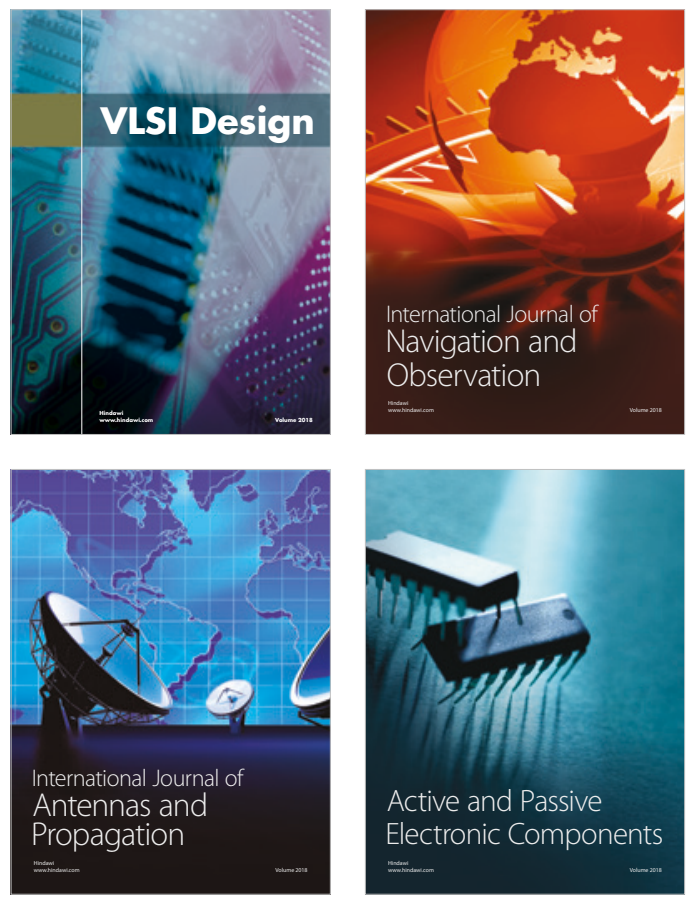
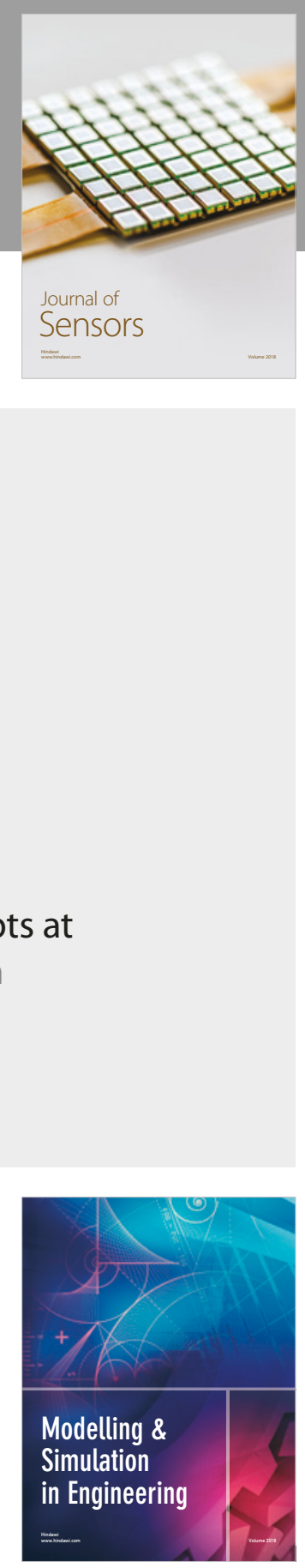

\section{Advances \\ Multimedia}
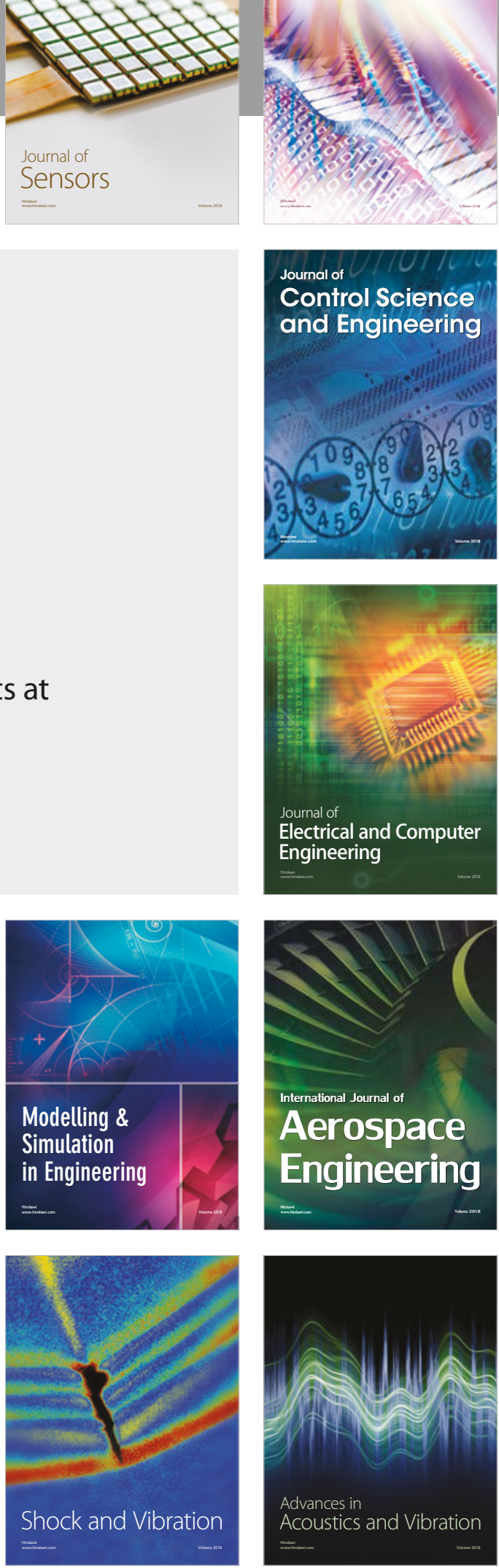